\title{
Requirements on Product Information Management in the Sales and Service Life-cycle Phases of a Plant
}

\author{
K. Jansson, I. Karvonen, I. Salkari, M. Ollus \\ VTT Automation, Technical Research Centre of Finland \\ Em:Kim.Jansson@vtt.fi
}

Keywords Information Management, Life-Cycle, Virtual Enterprise

\begin{abstract}
The information related to the delivery and operation of a plant is huge. Utilising this information and especially the experience-based knowledge can give business advantages. Operating in a network of organisations means to manage a large variety of processes and products in different locations, working environments and working conditions. This paper discusses some generic requirements on managing information in the sales and service lifecycle phases of Virtual Enterprises. Enterprises should prepare themselves for upstream information management.
\end{abstract}

\section{INTRODUCTION}

Selling, engineering, delivering, operating and maintaining a plant or factory are information intensive processes. The demand on efficiency, economy and environmental friendliness is increasing. The competition has moved from local and regional to global markets. To respond to these increasing demands collaboration over time zones and cultural boarders is needed. Operating in a network of organisations means to manage a large variety of processes and products in different locations, working environments and working conditions.

The IMS Globemen project addresses several of these issues. The objective of this paper is to present some findings regarding requirements on information management in the project. Project partners have their individual requirements and special considerations due to differences in products delivered, operation environment, cultural and working 
environments etc. This paper summarises the individual requirements and discusses some generalised requirements. The generalisation is also based on findings from other ongoing work and past projects.

All discussions concerning present and future IT-tools have intentionally been left out from this paper. It is thus rather obvious that the Internet and Web-based techniques together with mobile and wireless systems will have a dominating role as an enabler for change.

\section{SCOPE DEFINITION}

The total management of information over the life-cycle of a plant is a huge task. The area is the object for research and development work, which has produced information systems often call PDM and CRM system. The area is too large for a short paper like this and focusing is needed.

The industrial segment of this generalisation is one-of-a-kind products, e.g. plants and large sophisticated equipment. Often the products are so big and complicated that collaboration is needed to market, engineer, deliver operate and maintain the products. Typically enterprise networks and Virtual Enterprises (VE) are involved [3].

Another way to focus is on the management of processes and activities to support customers' use of the product irrespective of time and distance, that is to look at the both ends of the life-cycle. Typical activities include sales, services, operation, maintenance and renewal of equipment at customer sites.

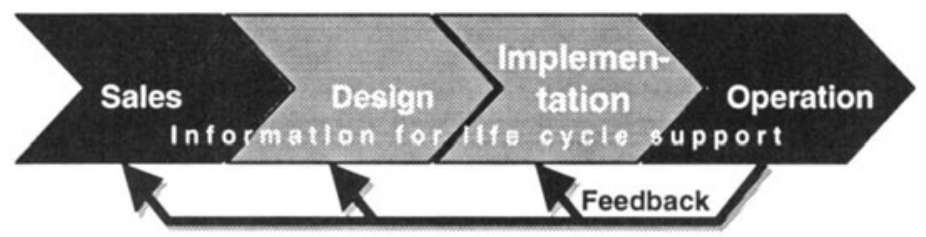

Figure 1. Scope of the paper

\section{BUSINESS OBJECTIVES FOR VIRTUAL ENTERPRISE PARTNERS}

Depending on life-cycle, the life-cycle phase may contain different actors like project engineers and contractors, equipment supplier, plant operator or local supplier. The business objectives and main business functions can to some degree be different, however many business objectives are coinciding irrespectively of what role the actor represents in the business network. One common and major industrial objective is to 
deliver products that are leading in their respective field or branch of business. In one-of-a-kind manufacturing there are additional challenges of keeping delivery time short and costs low enough and keeping the quality delivering process at a level that satisfies the customers.

The management of the sales process may support these business objectives by creating for the delivery a good starting point that allows a fast set-up of the delivery project and the virtual enterprise after the contract. The objective of being a supplier of choice also requires supporting the customers to identify their potential in the utilisation and updating of technology and systems. This needs the follow-up of competitors and evolving technologies.

For the equipment provider knowing how a machine or equipment has been used and how the equipment has functioned in customer environments gives valuable information. This information can be used in $\mathrm{R} \& \mathrm{D}$ for improving the equipment or designing the next generation of it.

Project engineers and delivery project contractors have the same business objectives as the equipment provider, that is, the whole plant, it's usage and operational environment. Additionally utilising information related to the project delivery, time and cost is relevant.

Service providers can give value to the customer and thus also increase the competitiveness of the manufacturer by offering advanced service and online operation support for the product

\section{DIRECTIONS OF INFORMATION INTEGRATION}

Within each life-cycle phase various requirements exist on information access, availability, reliabilities etc. ending up in IT-system requirements. These aspects are of course important and there are still areas within each phase that can be improved.

The integration of information over life-cycle phases is a matter, which holds great potential for improvements. The integration over life-cycle phases has two directions.

\subsection{Downstream information integration}

This is the "traditional" direction. The integration issues become interesting and more complex when the life-cycle steps involve different organisations in Virtual Enterprises. Figure 2 illustrates two of the dimensions for information integration. First downstream, within one plant life-cycle (Project 1 in the figure) there is risk of loosing valuable 
information when the product is handed over from the project supplier to the user or operator organisation.

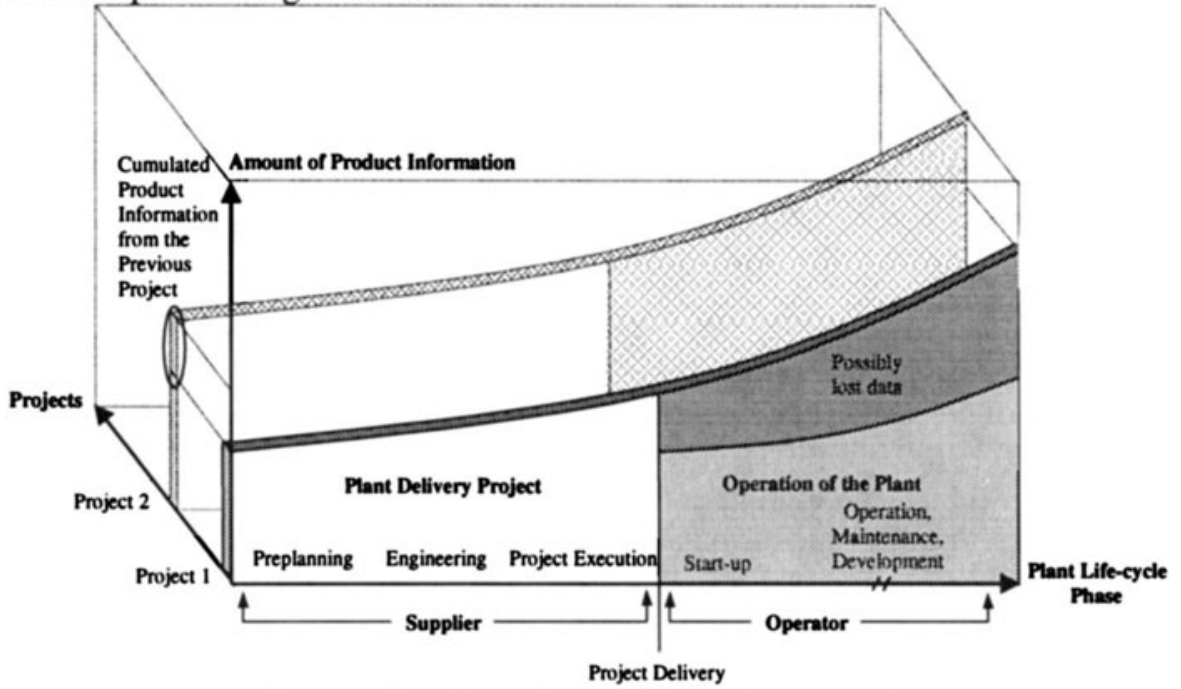

Figure 2. Two dimensions of Information Integration

\subsection{Upstream information integration}

The upstream integration can be seen in several ways depending on which life-cycle view is taken. In general it is collecting information on how the equipment or plant has been delivered and how the equipment or plant has been used, in which modes of operation and environments. Thus the second dimension shown in figure 2 is how the experience cumulated can be used in subsequent projects (Project 2 in the figure) resulting in a higher degree of knowledge. This knowledge is then used when improving and modernising existing plants

- when preparing contract offers to customers

- when designing new plants

- in research and development

- for operator training

- for supporting delivery projects

- for quick online support and remote diagnostics

\section{INTER ENTERPRISE INFORMATION EXCHANGE}

The following table gives an introduction to inter enterprise information content in the life-cycle phases under study. Knowledge, information and data are intellectual property and not always free and readily available, nor is it always available in the wanted format. Working according to the VE 
parading strives to remove some of the still existing obstacle in inter enterprise information exchange. Still there are open issues like:

Table 1. Life-Cycle Phase, Business Functions and Main Information Content Needed

\begin{tabular}{|c|c|c|}
\hline Life-Cycle Phase & Business Function & Main Information Content \\
\hline Marketing & $\begin{array}{l}\text { Market research } \\
\text { Sales planning } \\
\text { Network / Business partner } \\
\text { management }\end{array}$ & $\begin{array}{l}\text { Market segment development } \\
\text { Customer needs and future } \\
\text { interest } \\
\text { Information on competitors } \\
\text { Existing competencies at business } \\
\text { partners }\end{array}$ \\
\hline Sales & $\begin{array}{l}\text { Project planning } \\
\text { Product configuration } \\
\text { Bid preparation }\end{array}$ & $\begin{array}{l}\text { Customer requirements } \\
\text { specification } \\
\text { Technical solutions specifications } \\
\text { Cost information } \\
\text { Information on suppliers and their } \\
\text { previous performance } \\
\text { Experience from previous bids, } \\
\text { projects and deliverers }\end{array}$ \\
\hline R\&D & $\begin{array}{l}\text { Technology innovation research } \\
\text { Product development and } \\
\text { innovation } \\
\text { Presales engineering }\end{array}$ & $\begin{array}{l}\text { Technology trends } \\
\text { Market development and } \\
\text { requirements } \\
\text { Operational experience from } \\
\text { products in use }\end{array}$ \\
\hline Operation support & $\begin{array}{l}\text { (Remote) Customer training } \\
\text { (Remote) Process optimisation } \\
\text { and simulation } \\
\text { Service and maintenance } \\
\text { (Remote) Diagnostics, } \\
\text { troubleshooting } \\
\text { On-line information support }\end{array}$ & $\begin{array}{l}\text { Product behaviour, machine } \\
\text { performance data } \\
\text { Process parameters } \\
\text { Operational product } \\
\text { Configuration } \\
\text { Maintenance needs } \\
\text { Manuals and instructions } \\
\text { Training data and material } \\
\end{array}$ \\
\hline $\begin{array}{l}\text { Renewal, } \\
\text { Continuous } \\
\text { improvement }\end{array}$ & $\begin{array}{l}\text { Feedback to research, } \\
\text { development and engineering }\end{array}$ & $\begin{array}{l}\text { Operational data } \\
\text { Problems } \\
\text { Reasons for design decisions } \\
\text { Renewal needs } \\
\text { Potential for improvement }\end{array}$ \\
\hline
\end{tabular}

- Marketing and sales related information is scattered and no single source exists. The information systems are heterogeneous.

- The information it is subjective and can be interpreted differently.

- In the marketing and sales phases the information is sensitive. Partners are not always willing to give out strategic information before any VE is created or agreements made. Possible business partners may be involved in other/competing networks.

- Contractors do not want to commit themselves to use a certain supplier. 
- Supplier my not be willing to revile all capacity and load information. It may affect the price negotiations.

- The operational user is not willing to give performance data to one contractor only. Competition among contractors may be preferred.

- The contractors' organisation is not prepared to take advantage of information collected from different locations.

- The time frame is long from $R \& D$ to actual product. It takes time to get operational feedback

\section{REQUIREMENTS ON INFORMATION MANAGEMENT}

The main principle and idea within the IT user community has for decades been, "Store information once in one location and use many times" and it is still valid. Companies are still struggling to meet this requirement and in fact it will never be $100 \%$ met. Working in Virtual Enterprises and sharing information over the communication network and organisation boarders have introduced new aspects and levels of difficulty to this.

From the previous section we can conclude that the characteristics of plant related information is manifold. Some characteristics are:

1. large and complex

2. redundant and overlapping

3. loose, imprecise, incomplete and uncertain

4. subjective

5. dynamic with different versions

6. irregular and in different format

7. no direct or logical links exist between information items

8. distributed physically on a global scale

9. reside on different media

10. used by heterogeneous systems

11. outlives the systems that generated and processed it

12. owned and shared by several organisations

13. of different confidentiality and sensitivity level

\subsection{Generalised Requirements on Information Management}

These information characteristics impose a lot of constraints and requirements on the management. Some generalised requirements on information access and usage are:

Anywhere \& Anytime. Today's dynamic working environments should not put any restrictions on this. Companies are working in networks 
regardless of geographical location and time zones. Information must be available regardless of the local time.

Sensitivity \& Security. Trust and confidence between business partners operating in Virtual Enterprises cannot be built over-night. It requires time and successful co-operation to build up. Even business partners co-operating in the same VE have different levels of confidence in each other. In one project companies may work together; on another one they may be competitors. The IT-systems need to have features by which the levels of confidence can be defined "individually" in a dynamic way.

Permanence \& Impermanence. No relationship is permanent. To respond to the dynamic characteristics of VEs, features in IT-systems are needed that can give access for a restricted time and then cut the access rights.

Personalise and role based. The amount of information is huge and it is increasing constantly. The user needs services that can personalise what is presented. The environment should be capable to learn and configure itself according to users preferences and habits. The same information will be personalised in different formats to different users through a rich user interface.

Manage Complexity. Future IT-systems should help users in the management of large amount of data of increasing complexity and in integration of information from different sources. Finding relations between data from different sources and possible identification and catching relations between data and rationale for the decision.

Connectivity. There are numerous information systems by different vendors used today in enterprises. A common IT-system platform cannot be agreed even between partners co-operating in one Network or VE. The connectivity between different IT-systems from different vendors is crucial. Reference architectures and standards are needed for inter enterprise information communication.

\subsection{General User Requirements for Marketing and Sales}

This section generalises the requirements on IT-system supporting the early stages of the life cycle.

Sharing of relevant sales information. For sales related information to be communicated there must be means to share it across non-homogeneous IT domains. There is no single database design or data architecture for the world; neither is there a single data dictionary that would enable disparate databases to be easily combined.

Efficient bid preparation. Usage of tools and knowledge management techniques for faster and more accurate bid process. Better communication 
between bid perpetration partners and the customer. Improve the reliability of produced bids. The management of product data (previous solutions or product models) helps to prepare a high-quality bid efficiently

Enable downstream information usage. During the sales phase an extensive amount of information is created to define and configure the customer solution. Advanced product design in the sales phase contributes to fast delivery of the product after the contract. The information from the sales phase should be made available for the customer delivery process.

Fast Virtual Enterprise set-up. Large one-of-kind products, like plants, cannot be delivered by one company alone; subcontractors and partners are needed for the delivery. If the set-up of the virtual enterprise for the delivery is started already in the sales phase, the delivery project can be activated faster.

\subsection{General User Requirements for After Sales and Service}

Below is a summary of generalised requirements on IT-system supporting the after sales and service phases of the life cycle. Like in the marketing and sale phase, also here the advanced management of information is in central position. Upstream information integration in VEs is a novel requirement. The general requirements for IT-support include:

Feedback of product operational information to development, design and manufacturing. Shortening of lead-time at introducing or modifying equipment. Manufacturers of complex one-of-a-kind products, intend to co-operate with their globally spread customers to improve their operation-support and maintenance and to identify the needs for innovation. Thus they have to establish a global service for maintenance and operation support and a proper feed back of information about operation experience to $\mathrm{R} \& \mathrm{D}$. Therefore they need methods and tools for setting up communication, information exchange and sharing and also for analysing process information.

Fast access to process data for service and maintenance. Shortening of troubleshooting time during maintenance is desired. Manufacturers of complex one-of-a-kind products need appropriate processes and organisational design to shorten reaction time for service and maintenance and to use process data for fault analysis and simulation. This can increase plant availability, product quality and decrease production cost for the customer. The service partners need decreased access time to plant, process and maintenance knowledge, increased quality of provided knowledge and world-wide access to the knowledge.

Up-to-date product document maintenance. The product documentation must be maintained during the operational phase. This 
includes as well operators interactions, training material, simulation models and change history. Multimedia based documentation is emphasised.

\section{CONCLUSION}

Downstream information management, even over company boarders, is something that organisations and enterprises have desired for and struggled with for years. The organisational culture is starting to be prepared for this. The upstream inter-enterprise information management is a newer issue. The technology for this is starting to be in place. Delivering the information across enterprise borders is, however, not self-evident. It requires definition of rules and business procedures for creation, sharing, processing and using this inter enterprise information. As the experience based information is cumulated over time, it is also a task that requires longer perspectives and co-operation between the partners.

Are organisations prepared for upstream information integration? What happens if and when experience based information and knowledge suddenly is available? Are organisations prepared to take full advantage of the information?

One of the findings in the analysis work is that upstream information integration is a most interesting topic today. It is also the opinion of the authors that the companies need to prepare themselves to utilise experience based operational information.

\section{REFERENCES}

[1] Karvonen I., Jansson K. (1999). Project Information Management in Distributed One-ofkind Manufacturing Proceedings of the NORDNET Managing Business by Projects, Volume 2" Helsinki 1999

[2] Bernus P., Mertins K., Schmidt G (Eds.) Handbook on Architectures of Information Systems Springer Verlag 1998

[3] Kaas-Pedersen C., Larsen L-B., Vesterager J. Modelling Overview Report No D1.1 Globeman web site http://www.vtt.fi/aut/projects/gm21/demo/

[4] Salkari I, Managing Information over the Life Cycle of a Process Plant, Individual Assignment in Industrial Management, Helsinki University of Technology 2000

[5] Karvonen I., Management of one-of-a-kind manufacturing projects in a distributed environment, VTT Research Notes 2044, Technical Research Centre of Finland 2000 